\title{
NOVEL BICONICAL ANTENNA CONFIGURATION WITH DIRECTIVE RADIATION
}

\author{
M. Shahpari and F. Hojjat Kashani \\ Iran University of Science and Technology \\ Tehran, Iran

\section{H. Ameri} \\ Center of Research in Applied Electronics \\ University of Malaya \\ Malaysia
}

\begin{abstract}
In this paper a novel biconical antenna geometry has been proposed that has directive radiation pattern, higher gain and enhanced front to back ratio. Wide band performance is another characteristic of this new antenna.
\end{abstract}

\section{INTRODUCTION}

Wide band and ultra wide band systems are growing dramatically and upon this demand on antennas to have ultra wide band performance has been very serious requirement. Scientific journals have too many articles in this subjects recently [1-15]. Biconical antennas were introduced many years ago as wide band antenna and scientists and engineers have published many papers on this subject and some books have sections on this type of antenna. Wideband operation of this antenna type is of interest and, suitable especially for wideband and ultra wideband applications.

Collin [16] and Schelkunoff [17] considered conical antenna structures in different cases and addressed various areas such as, general formulations, thin wire antenna, wide angel conical dipoles, antenna admittance, biconical antenna in inhomogeneous dissipative media, dielectric loaded biconical antenna, asymmetric biconical antenna, and so on. Input impedance and radiation characteristics

Corresponding author: M. Shahpari (morteza.shahpari@iee.org). 
of bicones are solved problems as well but, research on this famous antenna type has been extended up to now $[18,19]$.

Biconical antenna in free space has omni directional pattern in $\mathrm{H}$ plane. Nagasawa and Matsuaka have reported directional biconicals using oblique edges [20]. They achieved directive antenna with low front to back ratio up to $6 \mathrm{~dB}$.

In this paper, novel configuration for biconical antenna is proposed. The proposed antenna is manufactured and tested. In addition to wideband operation it has directive pattern, higher gain and improved front to back ratio.

\section{NOVEL ANTENNA STRUCTURE}

Proposed antenna consists of two components, each component is a part of a cone that is illustrated in Figs. 1 and 2. Due to large conical flare angle authors have added a $5 \mathrm{~mm}$ end cylinder to save sharp edge. Narrow ground improves antenna front to back ratio and fixes cut cones in front of each other. Because of space limitations in the project such a narrow ground has been used with $80 \mathrm{~mm}$ and $280 \mathrm{~mm}$ dimensions with coaxial cable feed structure. Also dimensions of antenna have been selected with trial and error and are plotted in Fig. 2.

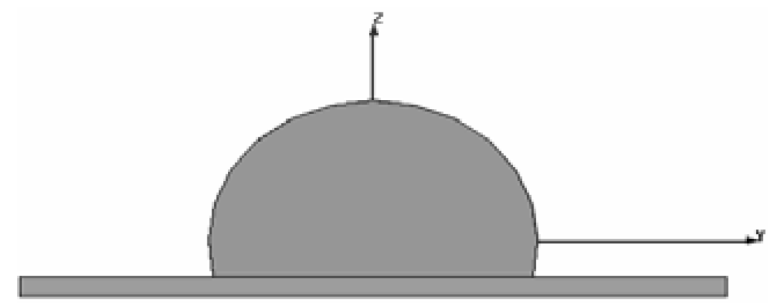

Figure 1. Antenna in $y-z$ plane (E-plane).

\section{SIMULATION AND TEST RESULTS}

The model had been simulated using commercial Ansoft HFSS package. Simulation has been done by a setup frequency at $3 \mathrm{GHz}$ (highest frequency in the range). Fast frequency sweep from $1 \mathrm{GHz}$ up to $3 \mathrm{GHz}$ has been employed to calculate accurate $S$-parameters and Return Loss. Also radiation characteristics of antenna have been simulated using a discrete sweep from $1 \mathrm{GHz}$ up to $3 \mathrm{GHz}$ with $100 \mathrm{MHz}$ frequency steps. 


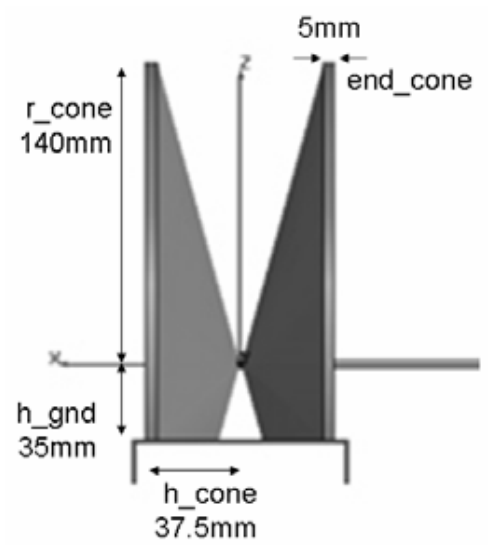

Figure 2. Antenna structure and its dimensions in $x-z$ ( $E$-plane).

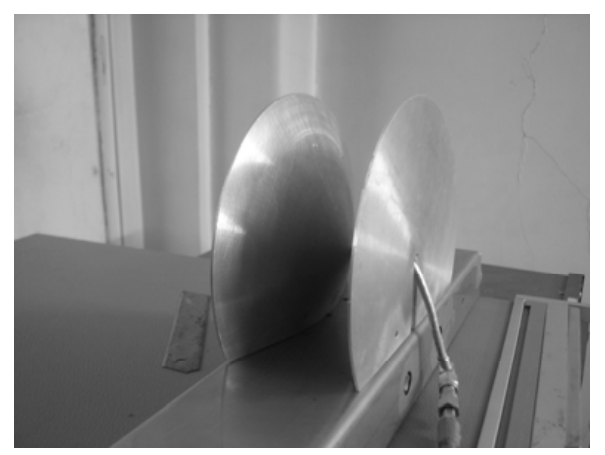

Figure 3. Three dimensional view of fabricated antenna.

Figures 4, 5, 6 show simulated $E$-Plane and $H$-plane at $1.2 \mathrm{GHz}$, $2 \mathrm{GHz}$ and $3 \mathrm{GHz}$. All patterns have been scaled to dB. Green, black and red patterns are test, simulated co-polarized and cross-polarized patterns. The most noticeable property is improvement in front to back ratio from $6 \mathrm{~dB}$ in [5] to $20 \mathrm{~dB}$ and more. Although some difference between simulation and measurement has been observed in the above figures (measurement shows more directive and improved front to back level), authors describe this difference as the limits of simulation and manufacturing errors that are inherent.

Antenna gain could not be measured because there was no access to reference antenna in this band to calculate gain; but realized gain in simulation software is depicted in Fig. 7. Fig. 8 illustrates simulation and measured antenna return loss. 


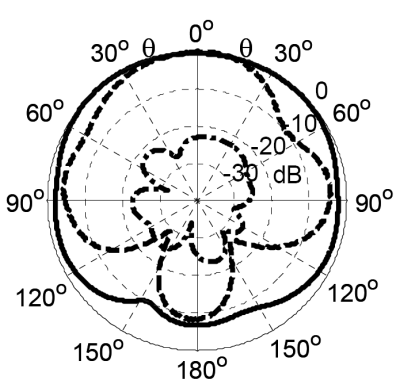

(a)

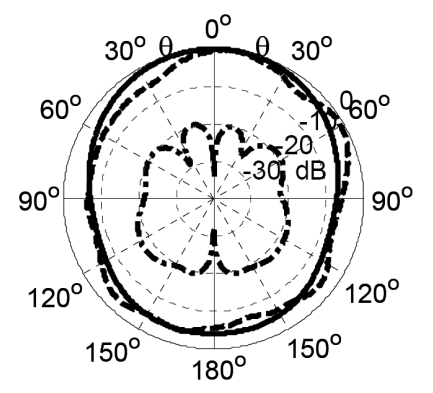

(b)

Figure 4. Radiation pattern at $1.2 \mathrm{GHz}$. (a) $E$-plane, (b) $H$-plane.

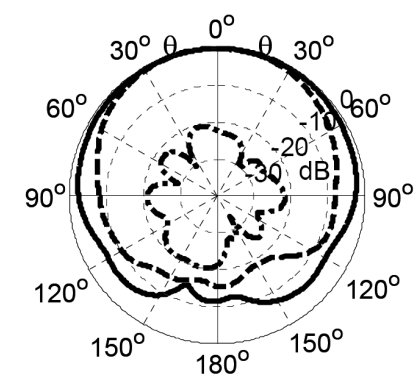

(a)

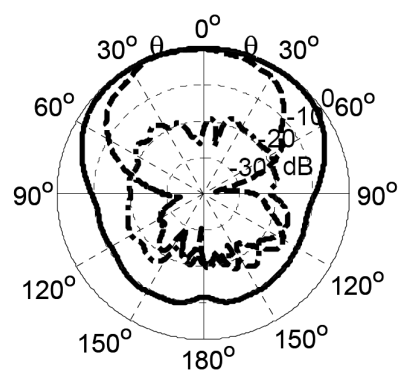

(b)

Figure 5. Radiation pattern at $2 \mathrm{GHz}$. (a) $E$-plane, (b) $H$-plane.

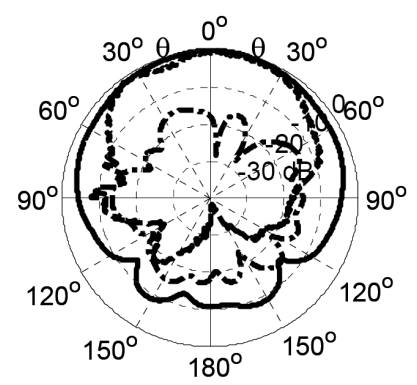

(a)

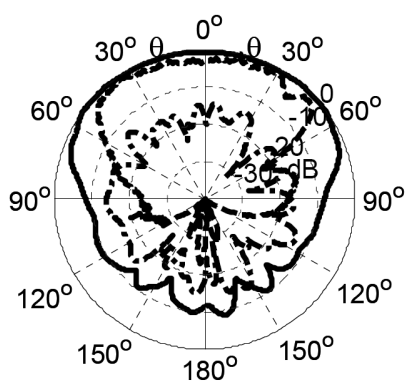

(b)

Figure 6. Radiation pattern at $3 \mathrm{GHz}$. (a) $E$-plane, (b) $H$-plane. 


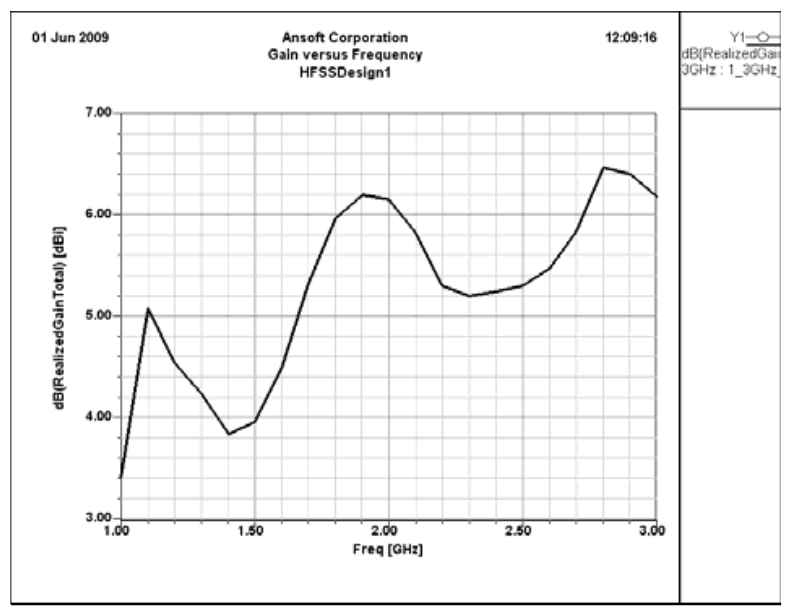

Figure 7. Simulated antenna gain in dBi versus frequency.

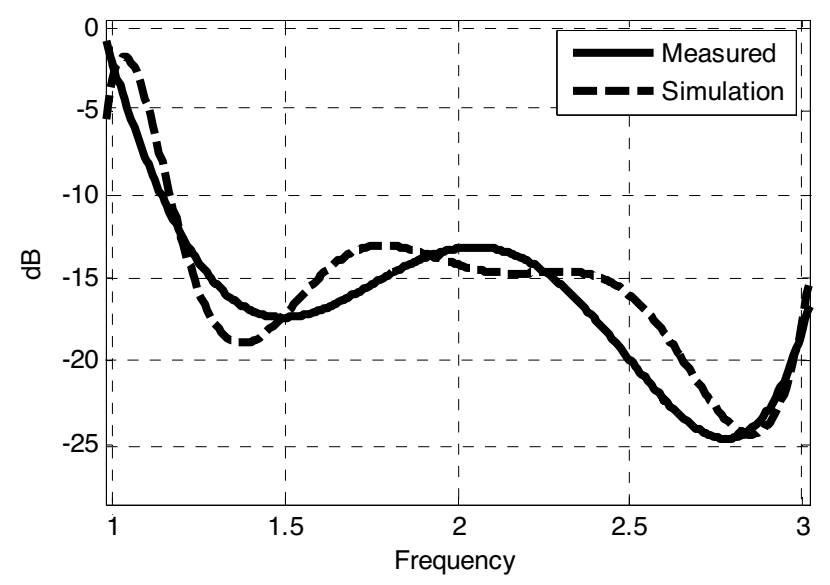

Figure 8. Antenna return loss (dB).

\section{CONCLUSION}

In this paper novel biconical antenna geometry has been proposed and tested that has directive radiation pattern. Antenna gain is about $4 \mathrm{dBi}$ to $6 \mathrm{dBi}$ in simulation and front to back ratio is greater than $20 \mathrm{~dB}$ in practice and simulation. Wide band performance is the other characteristic of this new antenna with return loss less than $13 \mathrm{~dB}$. 


\section{REFERENCES}

1. Pozar, D. M., "Optimal radiated waveforms from an arbitrary UWB antenna," Antennas and Propagation, IEEE Transactions on, Vol. 55, Issue 12, 3384-3390, Dec. 2007.

2. Zaker, R., C. Ghobadi, and J. Nourinia, "A modified microstripfed two-step tapered monopole antenna for uwb and wlan applications," Progress In Electromagnetics Research, PIER 77, 137-148, 2007.

3. Duroc, Y., A. Wang, T. P. Vuong, and S. Tedjini, "UWB antennas: Systems with transfer function and impulse response," Antennas and Propagation, IEEE Transactions on, Vol. 55, Issue 5, 14491451, May 2007.

4. Zhang, H.-T., Y.-Z. Yin, and X. Yang, "A wideband monopole with g type structure," Progress In Electromagnetics Research, PIER 76, 229-236, 2007.

5. Ghosh, D., A. De, M. C. Taylor, T. K. Sarkar, M. C. Wicks, and E. L. Mokole, "Transmission and reception by ultra-wideband (UWB) antennas," Antennas and Propagation Magazine, IEEE, Vol. 48, Issue 5, 67-99, Oct. 2006.

6. Jiao, J.-J., G. Zhao, F.-S. Zhang, H.-W. Yuan, and Y.-C. Jiao, "A broadband CPW-fed T-shape slot antenna," Progress In Electromagnetics Research, PIER 76, 237-242, 2007.

7. Ang, B.-K. and B.-K. Chung, "A wideband E-shaped microstrip patch antenna for 5-6 GHz wireless communications," Progress In Electromagnetics Research, PIER 75, 397-407, 2007.

8. He, J., B.-Z. Wang, Q.-Q. He, Y.-X. Xing, and Z.-L. Yin, "Wideband X-band microstrip butler matrix," Progress In Electromagnetics Research, PIER 74, 131-140, 2007.

9. Kang, K. K., J. W. Lee, C. S. Cho, K. T. Lee, "An improved impedance bandwidth of modified UWB antenna with staircased parasitic rings," Antennas and Wireless Propagation Letters, IEEE, Vol. 6, 521-524, 2007.

10. Boutayeb, H., T. A. Denidni, and M. Nedil, "Bandwidth widening techniques for directive antennas based on partially reflecting surfaces," Progress In Electromagnetics Research, PIER 74, 407419, 2007.

11. Sadat, S., M. Houshmand, and M. Roshandel, "Design of a microstrip square-ring slot antenna filled by an h-shape slot for uwb applications," Progress In Electromagnetics Research, PIER 70, 191-198, 2007.

12. Sadat, S., M. Fardis, F. G. Kharakhili, and G. Dadashzadeh, 
"A compact microstrip square-ring slot antenna for uwb applications," Progress In Electromagnetics Research, PIER 67, 173-179, 2007.

13. Eldek, A. A., "Numerical analysis of a small ultra wideband microstrip-fed tap monopole antenna," Progress In Electromagnetics Research, PIER 65, 59-69, 2006.

14. Mallahzadeh, A. R., A. A. Dastranj, and H. R. Hassani, "A novel dual-polarized double-ridged horn antenna for wideband applications," Progress In Electromagnetics Research B, Vol. 1, 67-80, 2008.

15. Wang, F. J., J.-S. Zhang, X.-X. Yang, and G.-P. Gao, "Time domain characteristics of a double-printed UWB dipole antenna," Progress In Electromagnetics Research Letters, Vol. 3, 161-168, 2008.

16. Collin, R. E. and F. J. Zucker, Antenna Theory, Part 1, 483-522, McGraw-Hill, NY, 1969.

17. Schelkunoff, S. A., Advanced Antenna Theory, Ch. 2, 3, D. Van Nostrand company, Inc., Princeton, NJ, 1952.

18. McDonald, J. L. and D. S. Filipovie, "On the bandwidth of monocone antennas," IEEE Transactions on Antennas and Propagation, Vol. 56, No. 4, April 2008.

19. Kim, K. H., J. U. Kim, and S. O. Park, "An ultrawide-band double discone antenna with the tapered cylindrical wires," IEEE Transactions on Antennas and Propagation, Vol. 53, No. 10, October 2005.

20. Nagasawa, K. and I. Matsuzuka, "Radiation field of biconical horn antenna with oblique edges," Conf. 1990 IEEE Int. Sym. Antennas and Propagation Society, Vol. 1, 527-530, 1990. 